\title{
Nf||l Media \\ POTENSI ANTIBAKTERI EKSTRAK DAUN JARAK PAGAR (Jatropha Curcas L.) TERHADAP STAPHYLOCOCCUS AUREUS DENGAN METODE DILUSI CAIR TERMODIFIKASI DAN DIFUSI AGAR
}

\author{
Antibacterial Potential Of Leaf Extract (Jatropha curcas l.) Against Staphylococcus aureus by Modified \\ Liquid Dilution And Agar Diffusion Methods.
}

\author{
Sesilia Rante Pakadang ${ }^{*}$, Sisilia Teresia Rosmala Dewi ${ }^{1}$, Tahir Ahmad ${ }^{1}$, Iip Prihartini ${ }^{2}$, Fausiah \\ Razak $^{2}$ \\ ${ }^{1}$ Politeknik Kesehatan Kemenkes Makassar \\ ${ }^{2}$ Universitas Pancasakti \\ *Koresponden E-mail: mamajassy@gmail.com
}

DOI: https://doi.org/10.32382/mf.v17i1.1968

\begin{abstract}
Jatropha curcas L. plant is widely known in Indonesian traditional medicine. The leaves and sap are often used as anti-infective drugs for sore mouth and throat. Therefore, this research aims to identify secondary metabolites contained in Jatropha leaf extract based on phytochemical screening, to determine the Minimum Inhibitory Concentration (MIC) and Minimum Killing Concentration (MKC) values based on the modified liquid dilution method. In addition, it also aims to determine the growth inhibition zone of Staphylococcus aureus based on the agar diffusion method. The concentration $(\% \mathrm{w} / \mathrm{v})$ tested in the liquid dilution method was $0.05,0.1,0.25,0.5,0.75,1,1.25,1.5,1.75,2$ and 2.25. Furthermore, amoxicillin 30 ppm was used as positive control and $1 \% \mathrm{Na} C M C$ as as negative control. The concentrations $(\% \mathrm{~W} / \mathrm{v})$ tested in the agar diffusion method were 1, 1.25, 1.5, 1.75, 2 and 2.25. The phytochemical screening results of the ethanol extract showed that it contain alkaloids, flavonoids, saponins, tannins and polyphenols. The liquid dilution results showed MIC and MKC concentration of 1.25 and $1.5 \% \mathrm{w} / \mathrm{v}$ respectively. Moreover, the inhibition zone diameter (concentration $\% / \mathrm{mm}$ of inhibitory power) obtained were $1 / 10.66,1.25 / 11,1.5 / 11,33,1.75 / 12,33,2 / 13$ and $2.25 / 14$. Based on the results, the statistically optimal concentration is determined at a concentration of $1.75 \% \mathrm{~W} / \mathrm{v}$.
\end{abstract}

Keywords : Jatropha leaves, Staphylococcus aureus, MIC, MKC, inhibition zone

\section{ABSTRAK}

Tanaman jarak pagar (Jatropha curcas L.) telah dikenal dalam pengobatan tradisional Indonesia. Daun dan getah jarak pagar sering digunakan sebagai obat antiinfeksi seperti radang mulut dan tenggorokan. Tujuan penelitian untuk mengidentifikasi senyawa metabolit sekunder yang terkandung dalm ekstrak daun jarak pagar berdasarkan skrining fitokimia, menentukan nilai Minimum Inhibitory Concentration (MIC) \& Minimum Killing Concentration (MKC) berdasarkan metode dilusi cair termodifikasi dan menentukan zona hambat pertumbuhan Staphylococcus aureus berdasarkan metode difusi aga Konsentrasi (\% b/v) yang diuji pada metode dilusi cair adalah 0,$05 ; 0,1 ; 0,25 ; 0,5 ; 0,75 ; 1 ; 1,25 ; 1,5 ; 1,75 ; 2$ dan 2,25. Kontrol positif digunakan Amoxicilin 30 ppm dan kontrol negatif yang digunakan adalah Na CMC 1\%. Konsentrasi (\% b/v) yang diuji pada metode difusi agar adalah 1;1,25; 1,5; 1,75; 2 dan 2,25. Hasil skrining fitokimia Ekstrak Etanol Daun Jarak Pagar mengandung senyawa alkaloid, flavonoid, saponin, tannin dan polifenol. Hasil pengujian dilusi cair dipeeroleh MIC dari pada konsentrasi 1,25\%b/v dan nilai MKC pada konsentrasi 1,5\%b/v. Hasil diameter zona hambat (konsentrasi \%/ mm daya hambat) yaitu 1/10,66; 1,25/11; $1,5 / 11,33 ; 1,75 / 12,33 ; 2 / 13$ dan 2,25/ 14. Konsentrasi optimal berdasarkan statistika ditentukan pada konsentrasi $1,75 \% \mathrm{~b} / \mathrm{v}$.

Kata kunci : Daun Jarak Pagar, Staphylococcus aureus, MIC, MKC, Zona hambat 


\section{PENDAHULUAN}

Tanaman jarak pagar sudah lama digunakan sebagai obat. Bagian yang sering digunakan adalah daun dan getahnya. Daun jarak pagar berpotensi mengobati berbagai macam infeksi yang disebabkan oleh bakteri. Kandungan metabolit sekundernya seperti fenol, flavanoid, alkaloid, dan saponin yang efektif untuk menghambat pertumbuhan bakteri Gram positif dan Gram negatif.

Pengujian ekstrak daun jarak pagar telah dilakukan dengan metode difusi agar. Berdasarkan daya hambat pertumbuhan bakteri maka ekstrak ekstrak etanol daun jarak pagar lebih efektif terhadap $E$ coli dibanding Staphylococcus aureus (Hasibuan, 2016). Ekstrak etanol daun jarak pagar juga terbukti menghambat pertumbuhan E. coli (Guranda dan Maulana, 2016) dan Staphylococcus aureus (Nursahfitri et al., 2020) dengan metode cakram difusi agar; dengan metode sumuran terhadap Enterococcus faecalis (Ichwani, 2017). Ekstrak etanol daun jarak juga telah diuji dengan metode difusi agar terhadap kerentanan Pseudomonas aeruginosa, Escherichia coli dan Shigella dysentriae (Rebecca et al., 2016).

Ekstrak methanol hasil ekstraksi metode reflux memberikan KHM 50.000 ppm dan hasil ekstrasi metode maserasi memberikan KHM 100.000 ppm terhadap Staphylococcus aureus dan Staphylococcus epidermidis (Yulianto dan Sunarmi, 2018). Minyak atsiri jarak pagar mengandung senyawa yang berpotensi sebagai antioksidan dan antimikroba terhadap beberapa strain pathogen. KHM berbeda untuk strain Gram-positif (0,3 mg / mL - 1,2 mg / mL) dan Gram. -negatif (0.6mg / mL-2.4mg / mL) (Babahmad et al., 2018).

Potensi penggunaan tanaman jarak pagar telah diuji dengan bentuk nanopartikel JcAgNps. Ekstrak nanopartikel diuji sebagai antibakteri dengan difusi cakram dan uji konsentrasi penghambatan / bakterisidal minimum (MIC / MBCs). Aktivitas terhadap Escherichia coli (MIC: $23 \mathrm{~mm}$, MBC: 0,010 $\mathrm{mg} / \mathrm{ml}$ ), Staphylococcus aureus (MIC: 14,66 mm, MBC: 0,041 mg/ml) dan Salmonella enterica (ZOI: 16,66 mm, MBC: 0,041 mg/ml) (Chauhan et al., 2016).

Meskipun beberapa penelitian terdahulu telah membuktikan potensi ekstrak daun jarak pagar (EDJP) sebagai antibakteri namun masih terbatas pada konsentrasi yang cukup besar bahkan 100\%. Hal ini kurang efektif untuk melanjutkan fungsi sebagai formula atau penggunaan di masyarakat, sehingga perlu dilakukan pencarian dosis efektif yang lebih kecil namun dapat memberikan potensi yang memadai sebagai suatu antimikroba dari bahan alam.

Penentuan konsentrasi aktif minimal dari ekstrak daun jarak pagar menjadi novelty dalam penelitian ini. Hal ini penting karena penggunaan ekstrak tanaman yang efektif bukan hanya karena potensinya dapat menghambat namun pada kadar berapa ekstrak tersebut dapat memberikan potensi yang optimal. Penggunaan bahan dengan dosis kecil yang efektif merupakan urgensi dalam peleitian ini. Metode dalam penelitian ini merupakan modifikasi dari metode yang ada untuk menyesuaikan jenis bahan uji yaitu ekstrak. Penentuan visual ekstrak berbeda dengan visual bahan uji terlarut yang jenih sehingga metode yang ada perlu dimodifikasi untuk mendapatkan pengamatan yang akurat.

\section{METODE}

Daun jarak pagar diperoleh dari Kabupaten Luwu Utara, Provinsi Sulawesi Selatan. Daun yang diambil adalah daun muda. Daun segar disortasi, dirajang kemudian dikeringkan dalam oven suhu $40-45^{\circ} \mathrm{C}$. Pelaksanaan penelitian dilakukan di laboratorium biologi farmasi jurusan farmasi Poltekkes Kemenkes Makassar. Simplisia kering diekstraksi dengan metode maserasi. Ekstrak kental daun jarak pagar yang diperoleh digunakan untuk melakukan untuk skrining fitokimia untuk identifikasi kandungan senyawa aktif dan pengujian aktivitas antibakteri secara dilusi cair dan difusi agar.

Skrining fitokimia dilakukan untuk mengidentifikasi senyawa: alkaloid, saponin, flavonois, tannin dan polifenol. Pengujian skrining fitokimia menggunakan reaksi warna dengan pereaksi yang sesuai. Uji Alkaloid. Ekstrak $\pm 0,5 \mathrm{~g}+2 \mathrm{~mL}$ etanol $70 \%$ dikocok +5 $\mathrm{mL} \mathrm{HCl} 2 \mathrm{~N}$, dipanaskan kemudian ditambah 3 tetes pereaksi Mayer akan terbentuk endapan. Uji Saponin. Ekstrak $\pm 0,5 \mathrm{~g}+2 \mathrm{~mL}$ etanol 70\% dikocok $+10 \mathrm{~mL}$ air suling dan dikocok, kemudian didiamkan 20 menit. Maka larutan menimbulkan busa. Uji Tanin. Ekstrak $\pm 0,5 \mathrm{~g}+$ $2 \mathrm{~mL}$ etanol $70 \%$ dikocok $+\mathrm{FeCl}_{3} 1 \% 3$ tetes, terjadi warna biru kehitaman jika senyawa tanin galat dan warna hijau kehitaman jika senyawa tannin katekin. Uji Flavonoid. Ekstrak $\pm 0,5 \mathrm{~g}+$ $2 \mathrm{~mL}$ etanol $70 \%$ dikocok $+0,5 \mathrm{~g}$ serbuk magnesium dan 3 tetes HCL pekat. Terbentuknya warna jingga sampai merah menunjukkan adanya flavon, merah sampai merah padam menunjukkan flavanol, merah padam sampai merah keunguan menunjukkan flavanon. Uji Polifenol. Ekstrak etanol $+10 \mathrm{~mL}$ air dan dipanaskan selama 10 menit, dinginkan dan disaring. Filtrat $+\mathrm{FeCL} 33$ tetes akan 
terbentuk larutan berwarna ungu sampai biru. (Putra et al., 2018)

Metode pengujian dilusi cair pada penelitian ini merupakan modifikasi dari metode standar Lay (2006). Pengujian aktivitas metode dilusi cair menggunakan ekstrak daun jarak pagar dengan konsentrasi $(0,05 \%),(0,1 \%)$, $(0,25 \%), \quad(0,5 \%), \quad(0,75 \%), \quad(1 \%), \quad(1,25 \%)$, $(1,5 \%),(1,75 \%),(2 \%),(2,25 \%)$. Pembanding menggunakan control positif amoksisilin $30 \mathrm{ppm}$ dan $\mathrm{Na} \mathrm{CMC} 0,1 \%$ sebagai control negative. Metode dilusi dilakukan dengan cara menyiapkan 4 seri media nutrient broth untuk setiap bahan uji. Kemudian masing-masing bahan uji dimasukkan dalam 4 seri media NB steril sejumlah $1 \mathrm{ml}$. Selanjutnya masukkan suspense bakteri uji Staphylococcus aureus dengan tingkat kekeruhan yang setara Mc. Farland 0,5 sejumlah $0,05 \mathrm{ml}$ pada seri $1,2,3$ media. Media seri ke 4 tidak dimasukkan bakteri uji sebagai pembanding tingkat kekeruhan. Semua hasil inokulasi diinkubasi dalam incubator pada suhu $37^{\circ} \mathrm{C}$ selama $1 \times 24$ jam (untuk pengamatan MIC) dan $2 \times 24$ jam (untuk pengamatan MKC).

Pengujian aktivitas metode difusi agar menggunakan ekstrak daun jarak pagar dengan konsentrasi $(1 \%),(1,25 \%),(1,5 \%),(1,75 \%)$, $(2 \%),(2,25 \%)$. Metode difusi agar menggunakan media nutrient agar dan paper disk yang telah direndam dalam masing-masing bahan uji. Bakteri uji dengan tingkat kekeruhan setara Mc Farland 0,5 diinokulasikan secara merata pada permukaan media NA menggunakan swab steril. Kemudian paper disk mengandung bahan uji diletakkan pada permukaan inoculum. Pengujian dilakukan dengan replikasi $3 \mathrm{x}$ dan diinkubasi dalam incubator pada suhu $37^{\circ} \mathrm{C}$ selama $1 \times 24$ jam.

\section{HASIL}

Tabel 1. Hasil Uji Skrining Fitokimia Ekstrak Daun Jarak Pagar (Jatropha curcas L.)

\begin{tabular}{ll}
\hline \multicolumn{1}{c}{ Identifikasi Senyawa } & \multicolumn{1}{c}{ Hasil } \\
\hline Alkaloid & Positif \\
\hline Saponin & Positif \\
\hline Tanin & Positif \\
\hline Flavonoid & Positif \\
\hline Polifenol & Positif \\
\hline
\end{tabular}

Tabel 2. Hasil Pengujian Minimum Inhibitory Concentration (MIC) Ekstrak Etanol Daun Jarak Pagar (Jatropha curcas L.) Sebagai Antibakteri Staphylococcus aureus Setelah 1x24 Jam.

\begin{tabular}{|c|c|c|c|c|c|c|c|c|c|c|c|c|c|c|}
\hline \multirow{2}{*}{$\begin{array}{c}\text { Waktu } \\
\text { Pengamatan }\end{array}$} & \multirow{2}{*}{ Tabung } & \multicolumn{9}{|c|}{ Konsentrasi Ekstrak Daun Jarak pagar \% } & \multicolumn{4}{|c|}{ Kontrol } \\
\hline & & 0,05 & 0,1 & 0,25 & 0,5 & 0,75 & 1 & 1,25 & 1,5 & 1,75 & 2,0 & 2,25 & $(+)$ & $(-)$ \\
\hline \multirow{4}{*}{$1 \times 24$ Jam } & 1 & + & + & + & + & + & - & - & - & - & - & - & + & + \\
\hline & 2 & + & + & + & + & - & - & - & - & - & - & - & + & + \\
\hline & 3 & + & + & + & + & + & + & - & - & - & - & - & + & + \\
\hline & (C) 4 & - & - & - & - & - & - & - & - & - & - & - & - & - \\
\hline
\end{tabular}


Tabel 3. Hasil Pengujian Minimum Killing Concentration (MKC) Ekstrak Etanol Daun Jarak Pagar (Jatropha curcas L.) Sebagai Antibakteri Staphylococcus aureus Setelah 2x24 Jam.

\begin{tabular}{|c|c|c|c|c|c|c|c|c|c|c|c|c|c|c|}
\hline \multirow{3}{*}{$\begin{array}{c}\text { Waktu } \\
\text { Pengamatan }\end{array}$} & \multirow{2}{*}{\multicolumn{12}{|c|}{ Konsentrasi Ekstrak Daun Jarak pagar \% }} & \multirow{2}{*}{\multicolumn{2}{|c|}{ Kontrol }} \\
\hline & & & & & & & & & & & & & & \\
\hline & & 0,05 & 0,1 & 0,25 & 0,5 & 0,75 & 1 & 1,25 & 1,5 & 1,75 & 2,0 & 2,25 & $(+)$ & $(-)$ \\
\hline \multirow{4}{*}{$2 \times 24$ Jam } & 1 & + & + & + & + & + & - & - & - & - & - & - & + & + \\
\hline & 2 & + & + & + & + & + & + & - & - & - & - & - & + & + \\
\hline & 3 & + & + & + & + & + & + & + & - & - & - & - & + & + \\
\hline & (C) 4 & - & - & - & - & - & - & - & - & - & - & - & - & - \\
\hline
\end{tabular}

Keterangan :

(+) : : Ada Pertumbuhan Staphylococcus aureus

$(-) \quad$ : Tidak ada pertumbuhan Staphylococcus aureus

Kontrol (+) : Amoxicilin 30 ppm

Kontrol (-) : Na-CMC 0,1\%

(C) : : Sebagai Pembanding (tanpa menggunakan bakteri)

: Nilai MIC \& Nilai MKC

Tabel 4. Hasil Pengukuran Diameter Zona Hambatan (mm) Ekstrak Etanol Daun Jarak Pagar (Jatropha curcas L.) terhadap Pertumbuhan Staphylococcus aureus.

\begin{tabular}{|c|c|c|}
\hline \multirow[t]{2}{*}{ Bahan uji } & Replikasi & $\begin{array}{c}\text { Diameter zona hambat } \\
\text { pertumbuhan }(\mathrm{mm})\end{array}$ \\
\hline & & Staphylococcus aureus \\
\hline \multirow{4}{*}{$\begin{array}{c}\text { Ekstrak daun jarak } \\
\text { pagar } 1 \%\end{array}$} & 1 & 10 \\
\hline & 2 & 11 \\
\hline & 3 & 11 \\
\hline & Rerata & 10,66 \\
\hline \multirow{4}{*}{$\begin{array}{l}\text { Ekstrak daun jarak } \\
\text { pagar } 1,25 \%\end{array}$} & 1 & 11 \\
\hline & 2 & 10 \\
\hline & 3 & 12 \\
\hline & Rerata & 11 \\
\hline \multirow{4}{*}{$\begin{array}{c}\text { Ekstrak daun jarak } \\
\text { pagar } 1,5 \%\end{array}$} & 1 & 11 \\
\hline & 2 & 12 \\
\hline & 3 & 11 \\
\hline & Rerata & 11,33 \\
\hline \multirow{4}{*}{$\begin{array}{l}\text { Ekstrak daun jarak } \\
\text { pagar } 1,75 \%\end{array}$} & 1 & 13 \\
\hline & 2 & 13 \\
\hline & 3 & 11 \\
\hline & Rerata & 12,33 \\
\hline \multirow{4}{*}{$\begin{array}{c}\text { Ekstrak daun jarak } \\
\text { pagar } 2 \%\end{array}$} & 1 & 13 \\
\hline & 2 & 13 \\
\hline & 3 & 13 \\
\hline & Rerata & 13 \\
\hline \multirow{4}{*}{$\begin{array}{l}\text { Ekstrak daun jarak } \\
\text { pagar } 2,25 \%\end{array}$} & 1 & 14 \\
\hline & 2 & 13 \\
\hline & 3 & 15 \\
\hline & Rerata & 14 \\
\hline
\end{tabular}


Tabel 5. Hasil analisis Mann Whitney pengaruh konsentrasi ekstrak daun jarak pagar terhadap zona hambat pertumbuhan bakteri uji

\begin{tabular}{lllllll}
\hline Perlakuan & & \multicolumn{6}{c}{ Zona hambat pertumbuhan bakteri uji } \\
\cline { 3 - 7 } bahan uji & n & Mean & Std dev & Median & Min & Max \\
\hline Konst 1\% & 3 & 10,66 & 0,577 & $11,00^{\mathrm{a}, \mathrm{b}, \mathrm{c}}$ & 10,00 & 11,00 \\
Konst 1,25\% & 3 & 11,00 & 1,00 & $11,00^{\mathrm{a}, \mathrm{b}, \mathrm{c}}$ & 10,00 & 12,00 \\
Konst 1,5\% & 3 & 11,33 & 0,577 & $11,00^{\mathrm{a}, \mathrm{b}, \mathrm{c}}$ & 11,00 & 12,00 \\
Konst 1,75\% & 3 & 12,33 & 1,154 & $13,00^{\mathrm{a}, \mathrm{b}, \mathrm{c}, \mathrm{d}, \mathrm{e}}$ & 11,00 & 13,00 \\
Konst 2,0\% & 3 & 13,00 & 0,00 & $13,00^{\mathrm{d}, \mathrm{e}}$ & 13,00 & 13,00 \\
Konst 2,25\% & 3 & 14,00 & 1,00 & $14,00^{\mathrm{d}, \mathrm{e}}$ & 13,00 & 14,00 \\
\hline
\end{tabular}

Superscript ${ }^{\text {a,b,c,d,e }}$ menunjukkan tidak ada perbedaan antar kelompok perlakuan (berdasarkan uji Mann Whitney dengan nilai $\mathrm{p}<0,05$ )

\section{PEMBAHASAN}

Penelitian ini merupakan rangkaian pengujian untuk membuktikan potensi ekstrak daun jarak pagar (EDJP) sebagai antibakteri. Potensi antibakteri ditentukan oleh senyawa kimia yang terkandung dalam ekstrak berupa metabolit sekunder. Pembuktian potensi ekstrak sebagai antibakteri khususnya terhadap Staphylococcus aureus dilakukan dengan pengujian aktivitas daya hambat pertumbuhan bakteri. Efektivitas potensi antibakteri ekstrak terhadap Staphylococcus aureus dilakukan dengan penentuan nilai MIC dan MKC. Hasil penelitian ini telah menunjukkan bahwa EDJP berpotensi sebagai antibakteri Staphylococcus aureus secara in vitro. Hal ini membuktikan potensi empiris DJP sebagai obat radang mulut dan tenggorokan yang didukung oleh penelitian Tinpun et al. (2020) dengan penemuannya yaitu ekstrak lateks $J$. curcas dapat meningkatkan penyembuhan luka setelah cedera sel dengan mekanisme antibakteri dan antioksidan dari daun jarak pagar.

Hasil skrining fitokimia menunjukkan ekstrak daun jarak pagar mengandung senyawa alkaloid, saponin, flavonoid, tannin dan polifenol. Senyawa-senyawa kimia tersebut yang berpotensi sebagai antibakteri karena telah terbukti sebagai antibakteri dengan berbagai mekanisme. Beberapa tanaman seperti pare, asam jawa dan biji kelengkeng yang juga mengandung senyawa alkaloid, saponin, flavonoid, tannin dan polifenol telah terbukti menghambat dan membunuh bakteri Staphylococcus aureus (Pakadang dan Salim, 2020; Pakadang dan Salim, 2020; Ratnah dan Salasa, 2020). Demikian pula penelitian Rebecca et al. (2016) yang memperoleh hasil metabolit sekunder dari daun dan batang jarak pagar yaitu glikosida, flavonoid, fenol, tanin, steroid, gula reduksi dan terpenoid. Dimana senyawa- senyawa tersebut juga diklaim sebagai antibakteri.

Hasil pengujian efektivitas bahan uji dalam penelitian ini menunjukkan bahwa (EDJP) efektif menghambat pertumbuhan Staphylococcus aureus pada konsentrasi minimal $1,25 \% \mathrm{~b} / \mathrm{v}$ atau $12,5 \mathrm{mg} / \mathrm{ml}$ dan efektif membunuh Staphylococcus aureus pada konsentrasi $1,5 \%$ atau $15 \mathrm{mg} / \mathrm{ml}$ secara in vitro. Hal ini sejalan dengan penelitian sebelumnya yang bahkan telah membuat sediaan ekstrak daun jarak pagar dalam bentuk ukuran nanopartikel kemudian mengujia efektivitasnya sebagai antibakteri terhadap beberapa bakteri seperti Staphylococcus aureus dan menemukan. Diameter zona hambat yaitu $14,66 \mathrm{~mm}$ dan nilai MIC yaitu $0,041 \mathrm{mg} / \mathrm{ml}$ atau $0,41 \mathrm{mg} / \mathrm{ml}$. (Cauhan et al., 2016). Penelitian lainnya yang juga meneliti tanaman jarak pagar yaitu menggunakan minyak atsiri memperoleh hasil aktivitas antijamur pada tiga ragi dengan konsentrasi hambat minimum (MIC) berkisar antara $0,3 \mathrm{mg} / \mathrm{mL}$ dan $0,6 \mathrm{mg} / \mathrm{mL}$. minyak jarak juga bersifat antibakteri terhadap enam bakteri dengan hasil bilai MIC terhadap strain bakteri Gram positif $(0,3 \mathrm{mg} / \mathrm{mL}-1,2 \mathrm{mg} / \mathrm{mL})$ dan strain bakteri Gram.negatif $(0.6 \mathrm{mg} / \mathrm{mL}$ $2.4 \mathrm{mg} / \mathrm{mL}$ ) (Babahmad et al., 2018). Perbedaan hasil nilai MIC dan MKC yang ditemukan pada penelitian ini dengan penelitian sebelumnya disebabkan oleh perbedaan spesifikasi bahan uji yang digunakan dimana penelitian ini menggunakan ekstrak langsung dari hasil ekstraksi sedangkan penelitian lain menggunakan isolate minyak atsiri atau menggunakan teknologi nanopartikel dalam penyiapan bahan uji. Namun penelitian ini juga telah membuktikan efektivitas EDJP meskipun tanpa perlakuan khusus bahan aktif.

Pembuktian aktivitas antibakteri dari EDJP telah ditemukan oleh banyak peneliti termasuk hasil dari penelitian ini. Hasil 
penelitian menunjukkan bahwa EDJP terbukti berpotensi sebagai antibakteri khususnya terhadap Staphylococcus aureus dengan parameter zona hambat pertumbuhan bakteri. Penelitian ini menguji 6 konsentrasi yaitu 1\% b/v; $1,25 \%$ b/v; $1,5 \%$ b/v; $1,75 \%$ b/v; $2 \% b / v$; $2,25 \% \mathrm{~b} / \mathrm{v}$. Konsentrasi tersebut dipilih berdasarkan data sebelumnya yang menunjukkan nilai MIC pada konsentrasi $1,25 \%$ $\mathrm{b} / \mathrm{v}$ dan nilai MKC pada konsentrasi $1,5 \% \mathrm{~b} / \mathrm{v}$. Hasil pengamatan zona hambat pertumbuhan Staphylococcus aureus ditentukan berdasarkan diameter hambatan yang diperoleh 10,66 mm $14 \mathrm{~mm}$. Berdasarkan analisis statistic SPSS diperoleh data yang tidak normal meskipun homogen, sehingga data diolah dengan analisis non parametrik Kruskal Wallis dan memperoleh hasil nilai sig. 0,04 $<0,05$ yang berarti ada pengaruh pemberian EDJP terhadap pertumbuhan Staphylococcus aureus. Selanjutnya analisis Mann Whitney dilakukan untuk menentukan perbedaan pengaruh antar konsentrasi perlakuan. Hasil yang diperoleh menunjukkan bahwa konsentrasi 1,75\% merupakan konsentrasi yang optimal dalam penelitian ini. Hasil yang berbeda dengan nilai MIC dan MKC sebelumnya disebabkan oleh jumlah koloni yang digunakan dalam pengujian. Pada metode dilusi cair jumlah koloni bakteri uji yang digunakan terukur $(0,05 \mathrm{ml}$ dengan standar kekeruhan Mc Farland 0,5) sedangkan pada pengujian potensi menggunakan metode difusi agar menggunakan sejumlah bakteri uji (standar kekeruhan Mc Farland 0,5) dengan cara disebarkan menggunakan swab steril. Namun data yang dihasilkan memberikan nilai MKC pada $1,5 \% \mathrm{~b} / \mathrm{v}$ sedangkan konsentrasi optimal dalam penelitian ini adalah $1,75 \% \mathrm{~b} / \mathrm{v}$. Data ini dapat menjadi acuan sebagai konsentrasi pilihan untuk melanjutkan penelitian ini ke tingkat formulasi. Pembuktian aktivitas EDJP sebagai antibakteri juga telah dilakukan oleh peneliti sebelumnya yang menguji aktivitas EDJP terhadap Staphylococcus aureus konsentrasi $20 \%$ - 100\% dan menghasilkan zona hambat 13,5 $\mathrm{mm}-18,67 \mathrm{~mm}$ (Hasibuan, 2016). Selanjutnya Guranda dan Maulanza (2016) menguji aktivitas EDJP terhadap Escherichia coli dan menghasilkan data konsentrasi optimal sebagai antibakteri E. coli adalah konsentrasi $80 \%$ yang memberikan daya hambat 24,25 mm. Demikian pula peneliti Ichwani (2017) yang menguji aktivitas EDJP terhadap Enterococcus faecalis dengan konsentrasi bahan uji $6,25 \mathrm{gr} / \mathrm{daL} \quad-100$ gr/daL dan memberikan hasil zona hambat maksimal pada konsentrasi $100 \mathrm{gr} / \mathrm{daL}$. Yulianto dan Sunarmi (2018) telah membandingkan aktivitas ekstrak methanol daun jarak pagar yang diekstraksi dengan metode maserasi dan refluks pada konsentrasi $3,125 \mathrm{ppm}-100.000 \mathrm{ppm}$. Hasil yang diperoleh menunjukkan metode ekstraksi refluks menghasilkan ekstrak yang lebih efektif dalam menghambat pertumbuhan Staphylococcus epidermidis dan Staphylococcus aureus dengan zona hambat maksimal pada konsentrasi 100.000 ppm. Pada penelitian lain Tiwa et al. (2017) telah menguji aktivitas antibakteri getah daun jarak pagar terhadap Streptococcus mutans dan memberikan zona hambat maksimal $19 \mathrm{~mm}$. Penelitian lebih lanjut dengan teknologi nanopartikel untuk melihat efektivitas antibakteri dari ekstrak jarak pagar telah diteliti oleh Chauhan et al. (2016) dan Nayak et al. (2019). Keduanya memberikan data hasil antibakteri yang sangat efisien dengan konsentrasi yang efektif dengan kestabilan formulasi ekstrak nanopartikel.

\section{KESIMPULAN}

Berdasarkan hasil penelitian disimpulkan bahwa:

1. Ekstrak daun jarak pagar (Jatropha curcas L.) mengandung senyawa alkaloid, flavonoid, saponin, tannin dan polifenol.

2. Ekstrak daun jarak pagar (Jatropha curcas L.) efektif menghambat pertumbuhan dan membunuh Staphylococcus aureus dengan nilai MIC pada konsentrasi 1,25\% b/v dan nilai MKC pada konsentrasi $1,5 \% \mathrm{~b} / \mathrm{v}$ dengan metode dilusi cair termodifikasi.

3. Ekstrak daun jarak pagar (Jatropha curcas L.) dapat menghambat pertumbuhan Staphylococcus aureus dengan konsentrasi optimal pada $1,75 \mathrm{~b} / \mathrm{v}$.

\section{SARAN}

Disarankan untuk melanjutkan penelitian ini pada taraf formula atau pengujian efek antimikroba secara in vivo.

\section{DAFTAR PUSTAKA}

Babahmad RA., Aghraz A., Boutafda AB., Papazoglou EG., Tarantilis PA., Kanakis C., Hafisi M., Ouhdouch Y., Outzourhit A., Ouhammou A., (2018). Chemical composition of essential oil of Jatropha curcas L. leaves and its antioxidant and antimicrobial activities. Industrial Crops and Products. Volume 121, 1 October 2018, Pages 405-410

Chauhan N., Tyagi AK., Kumar P., Malik A., (2016). Antibacterial Potential of Jatropha curcas Synthesized Silver Nanoparticles against Food Borne Pathogens. Front. Microbiol., 08 
November

2016

https://doi.org/10.3389/fmicb.2016.017 48

Guranda I., Maulanza H. (2016). Uji effektfitas tanaman jarak pagar (jatropha curcas 1.) sebagai anti mikroorganisme pada bakteri Escherechia coli. Serambi Saintia, Vol. IV, No. 2, 42-49 Oktober 2016 ISSN : 2337 - 9952.

Hasibuan, S.A. (2016). Perbandingan daya hambat ekstrak daun jarak pagar (Jatropha curcas Linn) terhadap pertumbuhan Staphylococcus aureus dan Escherichia coli secara in vitro. Fakultas Kedokteran Universitas Lampung. Skripsi. http://digilib.unila.ac.id/21369/

Ichwani KS., 2017. Daya antibakteri ekstrak etanol daun jarak pagar (Jatropha curcas L.) terhadap pertumbuhan Enterococcus faecalis. Skripsi. Universitas Jember http://repository.unej.ac.id/handle/1234 56789/79487

Nayak S., Saiankila SP., Vaman C., Ashwathi R., Hedge R., Mutalik S., (2019). Biogenic synthesis of silver nanoparticles using Jatropha curcas seed cake extract and characterization: evaluation of its antibacterial activity. Journal Energy Sources. Received 29 Jan 2019, Accepted 27 May 2019, Published online: 24 Jun 2019.

Nursahfitri, Amalia R., Fadillah Q., (2020). Uji efektivitas antibakteri ekstrak daun jarak pagar (Jatropha curcas Linn) terhadap bakteri Staphyloccocus aureus. Jurnal Ilmiah Mahasiswa Kesehatan Masyarakat. Vol 5, No 4 (2020) : http://dx.doi.org/10.37887/jim kesmas.v5i4.15059

Pakadang SR., Halim H., (2020). The Effect Of Bitter Melon Leaf Extract (Momordica charantia L.) Towards The Growth Of Streptococcus

Staphylococcus pneumonia, epidermidis, Staphylococcus aureus And Klebsiella pneumonia As A Cause Of Acute Respiratory Infections. Media Farmasi p.issn 0216-2083 e.issn 2622-0962 Vol. XVI No.2, Oktober 2020. 207-214.
Pakadang SR., Halim., (2020). Sensitivitas Streptococcus pneumoniae, Staphylococcus aureus dan Staphylococcus epidermidis terhadap BUAH ASAM JAWA (Tamarindus indica L). Media Farmasi. Vol 16, No 1 (2020)

Putra GMD., Satriawaty DA., Astuti NKW., yadnya Putra AAGR., 2018. Standarisasi dan skrining fitokimia ekstrak etanol $70 \%$ daun jeruk limau (Citrus amblycarpa (Hassk.) Osche). Jurnal Kimia (Journal of Chemistry), [S.1.], p. 187-194, july 2018. ISSN 2599-2740.

Rebecca R., Samuel DD., Bello YM., Simeon OK., (2016). Qualitative Phytochemistry and Antibacterial Resistance Pattern of Leaves and Stem Bark Extracts of Jatropha curcas. American Journal of Microbiological Research, vol. 4, no. 5 (2016): 143-146. doi: 10.12691/ajmr-4-5-3.

Salasa AM., Ratnah St., (2020). Aktivitas Antimikroba Ekstrak Kulit Buah Kelengkeng (Euphoria longan Stend) Terhadap Pertumbuhan Candida albicans Dan Propionibacterium acne. Media Farmasi p.issn 0216-2083 e.issn 2622-0962 Vol. XVI No.2, Oktober 2020. 155-159.

Tinpun K., Nakpheng T., Padmavathi AR., Srichana T., (2020). In Vitro Studies of Jatropha curcas L. Latex Spray Formulation for Wound Healing Applications. Turk J Pharm Sci. 2020 Jun; 17(3): 271-279.

Tiwa FG., Homenta H., Hutagalung BSP., (2017). Uji efektivitas daya hambatgetah daun jarak pagar (Jatropha curcas L.) terhadap Streptococcus mutans. Pharmacon. Vol 6, No 4 (2017).

Yulianto S. dan Sunarmi (2018). Aktivitas antibakteri ekstrak daun jarak pagar (Jatropha curcas L.) terhadap Staphylococcus epidermidis dan Staphylococcus aureus secara in vitro. Jurnal Ilmu Kesehatan. Vol 7, No 1 (2018).

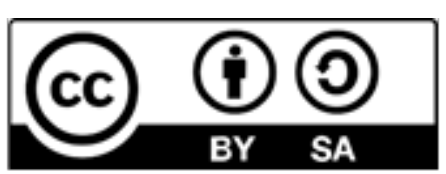

